\title{
High-Intensity Interval Training is Associated with Improved Long-Term Survival in Heart Failure Patients
}

\author{
Chih-Chin Hsu ${ }^{1,2,3}$, Tieh-Cheng Fu ${ }^{1,3,4}$, Shin-Sheng Yuan ${ }^{5, *, \dagger}$, Chao-Hung Wang ${ }^{4,6}$, \\ Min-Hui Liu ${ }^{4,7}$, Yu-Chiau Shyu ${ }^{3,8,9} \mathbb{D}$, Wen-Jin Cherng $10 \oplus$ and Jong-Shyan Wang ${ }^{11, *,+}$ \\ 1 Department of Physical Medicine and Rehabilitation, Keelung Chang Gung Memorial Hospital, \\ Keelung 204, Taiwan; steele0618@gmail.com (C.-C.H.); fic6481@gmail.com (T.-C.F.) \\ 2 School of Traditional Chinese Medicine, College of Medicine, Chang Gung University, Taoyuan 333, Taiwan \\ 3 Community Medicine Research Center, Keelung Chang Gung Memorial Hospital, Keelung 204, Taiwan; \\ yuchiaushyu@gmail.com \\ 4 Heart Failure Research Center, Cardiology Section, Department of Internal Medicine, \\ Keelung Chang Gung Memorial Hospital, Keelung 204, Taiwan; bearty54@cgmh.org.tw (C.-H.W.); \\ minimin624@gmail.com (M.-H.L.) \\ 5 Institute of Statistical Science, Academia Sinica, Taipei 115, Taiwan \\ 6 Division of Cardiology, Department of Internal Medicine, Keelung Chang Gung Memorial Hospital, \\ Keelung 204, Taiwan \\ 7 Department of Nursing, Ching-Kuo Institute of Management and Health, Keelung 203, Taiwan \\ 8 Institute of Molecular Biology, Academia Sinica, Taipei 115, Taiwan \\ 9 Department of Nursing, Chang Gung University of Science and Technology, Taoyuan 333, Taiwan \\ 10 Division of Cardiology, Department of Internal Medicine, Linkou Chang Gung Memorial Hospital, \\ Taoyuan 333, Taiwan; cwenjin@ms3.hinet.net \\ 11 Institute of Rehabilitation Science, Department of Physiotherapy, College of Medicine, \\ Chang Gung University, Taoyuan 333, Taiwan \\ * Correspondence: syuan@stat.sinica.edu.tw (S.-S.Y.); s5492@mail.cgu.edu.tw or \\ s120011676@gmail.com (J.-S.W.); Tel.: +886-2-27875737 (S.-S.Y.); +886-3-3211-8800 (ext. 5748) (J.-S.W.) \\ Fax: +886-2-2788-6833 (S.-S.Y.); +886-2-24315931 (J.-S.W.) \\ + Equal contribution as the corresponding author.
}

Received: 21 February 2019; Accepted: 19 March 2019; Published: 25 March 2019

check for updates

\begin{abstract}
This matched-control cohort study explored the effects of high-intensity interval training (HIIT) on left ventricle (LV) dimensions and survival in heart failure (HF) patients between 2009 and 2016. HF patients who underwent the multidisciplinary disease management program (MDP) were enrolled. Non-exercising participants, aged (mean (95\% confidence interval)) 62.8 (60.1-65.5) years, were categorized as the MDP group $(n=101)$. Participants aged 61.5 (58.7-64.2) years who had completed 36 sessions of HIIT were treated as the HIIT group $(n=101)$. Peak oxygen consumption $\left(\mathrm{VO}_{2 \text { peak }}\right)$ and $\mathrm{LV}$ geometry were assessed during the 8-year follow-up period. The 5-year all-cause mortality risk factors and overall survival rates were determined in the longitudinal observation. An increased $\mathrm{VO}_{2 \text { peak }}$ of $14-20 \%$ was observed in the HIIT group after exercise training. Each 1-mL/ $\mathrm{kg} / \mathrm{min}$ increase in $\mathrm{VO}_{2 \text { peak }}$ conferred a $58 \%$ improvement in 5-year mortality. Increased LV end-systolic diameter (LVESD) was significantly $(p=0.0198)$ associated with increased mortality. The 8-month survival rate was significantly improved ( $p=0.044)$ in HIIT participants compared to non-exercise participants. HF patients with $\mathrm{VO}_{2 \text { peak }} \geq 14.0 \mathrm{~mL} / \mathrm{kg} / \mathrm{min}$ and LVESD $<44 \mathrm{~mm}$ had a significantly better 5-year survival rate $(98.2 \%)$ than those $(57.3 \%)$ with lower $\mathrm{VO}_{2 \text { peak }}$ and greater LVESD. Both HIIT-induced increased $\mathrm{VO}_{2 \text { peak }}$ and decreased LVESD are associated with improved survival in HF patients.
\end{abstract}


Keywords: heart failure; cardiac rehabilitation; ventricular remodeling; oxygen consumption; cumulative survival rate

\section{Introduction}

Heart failure (HF) is caused by a structural or functional cardiac disorder that impairs ventricular relaxation or ejection [1] and affects approximately 26 million people in the world [2]. Population surveys have estimated HF prevalence at $2-3 \%$ in Western societies [3] and $1.26-6.7 \%$ in Asia [4]. The 1- and 5-year survival rates after the onset of HF in the Framingham study were approximately $70 \%$ and 50\%, respectively [5]. The estimated global burden of HF was $\$ 108$ billion USD in 2012 [6]. Therefore, care for HF patients has become a significant challenge in modern medicine owing to the high mortality and growing medical costs.

Although exercise intensity greater than $80 \%$ of peak oxygen consumption $\left(\mathrm{VO}_{2 \text { peak }}\right)$ corresponds to vigorous physical activity, supervised exercise training beyond this level has been recommended as a safe approach for aging people [7] and HF patients [8,9]. High-intensity interval training (HIIT) has been used as a form of interval training to improve the cardiorespiratory function in recent clinical practice and is characterized by alternating short periods of exercise at $\geq 80 \%$ of one's $\mathrm{VO}_{2 \text { peak }}$ with less intense (40-50\% of $\mathrm{VO}_{2 \text { peak }}$ ) recovery periods [7]. This exercise strategy has been shown to increase $\mathrm{VO}_{2 \text { peak }}$ by $10-20 \%$ in HF patients with different left ventricular ejection fraction (LVEF) [8-10]. HIIT also increases red blood cell deformability [11] and promotes cerebral/muscular hemodynamics [9]. Thus, HIIT has been advocated as a beneficial therapy for HF patients [8,9].

Studies have confirmed that moderate-intensity continuous exercise training (MICT) improves LVEF and reduces LV end-diastolic diameter (LVEDD) in patients with LVEF $\leq 40 \%$ (HFrEF: HF with reduced LVEF) [12,13]; these findings could not be detected in HF patients with LVEF > $40 \%$ (HFpEF: HF with preserved LVEF) [14]. Short-term HIIT-induced anti-remodeling effects on HFrEF patients, including boosted cardiac output (CO) and decreased LV volume, have been reported in previous literature [6,15]. However, the effects of short-term HIIT on overall survival and long-term LV remodeling features in HF patients remain unclear.

The present work was summarized from an 8-year cohort study for progression of LV geometry and survival in HF patients with and without HIIT during the longitudinal follow-up (F/U). With in-depth analysis on these long-term observations, we hoped to provide insights into the HIIT effects on LV remodeling and associated clinical outcomes in different types of HF patients, which might lead to better management for different types of HF patients.

\section{Methods}

\subsection{Participants}

This was a prospective matched-control study on a priori collected data, which followed the REporting of studies Conducted using Observational Routinely collected health Data (RECORD) and the STrengthening the Reporting of OBservational studies in Epidemiology (STROBE) recommendations [16]. The institutional review board of a community hospital approved the study protocol (201601068B0) and the clinical trial registry number is NCT03245125. A total of $541 \mathrm{HF}$ patients diagnosed according to the Framingham heart failure diagnostic criteria [17] were primarily surveyed for the candidate of exercise training between 1 January 2009 and 31 December 2016. Among them, $330 \mathrm{HF}$ patients with stable clinical presentations [18] $\geq 4$ weeks received the multidisciplinary disease management program (MDP) provided by our HF care team, who offered individualized patient education and optimized guideline-based management $[19,20]$. Those who were $\geq 80$ or $<20$ years old, were unable to exercise because of a non-cardiac disease, were pregnant, interrupted exercise training during $\mathrm{F} / \mathrm{U}$, were lost to $\mathrm{F} / \mathrm{U}$ at our cardiologic clinic, were candidates for cardiac 
transplantation within 6 months, were uncompensated HF patients, or were renal patients with an estimated glomerular filtration rate of $<30 \mathrm{~mL} / \mathrm{min} / 1.73 \mathrm{~m}^{2}$ were not eligible for exercise training. Patients who had absolute contraindications for cardiopulmonary exercise test (CPET) and aerobic activities, suggested by the American College of Sports Medicine (ACSM) [21], were also excluded from the study. The $234 \mathrm{HF}$ patients eligible for exercise trainings were further divided into exercise and non-exercise groups based on patient preference. All the participants provided informed consent before initiating the experimental procedure.

\subsection{Clinical Assessments}

Age, sex, and body mass index (BMI) were recorded for all included subjects. Serum levels of low-density lipoprotein (LDL), creatinine (Cre), glycohemoglobin (Hba1c), and cardiac stress-related b-type natriuretic peptide (BNP) $[15,22]$, were scheduled to be checked in all the recruited subjects at baseline and during F/U. The physical component score (PCS) and mental component scores (MCS) in the Medical Outcomes Study Short Form 36 (SF-36) were used to assess the quality of life (QoL) before each CPET. Echocardiography and CPET were performed during long-term F/U. The list of all variables is provided in supplemental Table S1.

\subsubsection{Echocardiography}

Cardiac images were acquired at end-expiration with a 2-5 MHz tightly curved-array ultrasound transducer (Vivid 7, General Electric Healthcare, Chicago, IL, USA or Phillips IE33, Philips Healthcare, Andover, MA, USA). M-mode echocardiography, proven to be highly reproducible with low variability and wealth of accumulated data [23,24], was used to measure LVEDD, LV end-systolic diameter (LVESD), and LVEF for all subjects. HF patients with LVEF of $\leq 40 \%$ were classified as having HFrEF, and those with LVEF $>40 \%$ were classified as having HFpEF based on their baseline echocardiographic findings [9].

\subsubsection{Cardiopulmonary Exercise Test}

The participants underwent an incremental exercise test on a bicycle ergometer (Ergoselect 150P, ergoline $\mathrm{GmbH}$, Bitz, Germany), which was performed at a work-rate of $10 \mathrm{~W} /$ min with continuous monitoring heart rate (HR), brachial blood pressure, and arterial oxygen saturation, until the stopping conditions described previously [25]. Oxygen consumption was measured breath by breath using a MasterScreen CPX (CareFusion, Hoechberg, Germany), and the $\mathrm{VO}_{2 \text { peak }}$ was defined as the guideline for exercise testing suggested by the ACSM [21].

\subsection{Interventions}

HF patients with MDP who underwent an additional 36 sessions (2-3 sessions/week) of supervised hospital-based exercise training on a bicycle ergometer in 3-4 months as the previous protocol $[9,26]$ were classified as the HIIT group (MDP+HIT). The HIIT protocol was performed as five 3-min intervals at $80 \% \mathrm{VO}_{2 \text { peak, }}$, and each interval was separated by 3-min exercise at $40 \%$ $\mathrm{VO}_{2 \text { peak }}[9,25]$. The exercise training was terminated when the subject had symptoms/signs during HIIT in accordance with the ACSM guideline [21]. Home exercise programs were not suggested for the HIIT participants. The others without supervised exercise training received advice for home-based physical activities and were classified as the MDP group.

\subsection{Follow-Up}

The participants were followed up until 31 December 2016, or when death occurred during the observational period. All the HF patients were assessed at the time of recruitment. All the HIIT participants underwent secondary CPET, echocardiography, and blood tests within 1 week after completing HIIT. The HIIT participants were scheduled to have echocardiographic examinations 
every 6 months after completing 36 sessions of HIIT. MDP participants were also scheduled to receive the echocardiographic examination every 6 months during F/U. Dates and causes of death were also documented.

\subsection{Statistical Analysis}

\subsubsection{Longitudinal Analysis}

Baseline demographic information between the HIIT and MDP groups were compared by Student's $t$ test or Mann-Whitney U test (for deceased subjects) for continuous variables, and the chi-squared test for nominal variables. The paired sample $t$-test was used to assess HIIT effects on $\mathrm{VO}_{2 \text { peak, }}$ peak $\mathrm{HR}$, peak $\mathrm{O}_{2}$ pulse, cardiac geometry, and QoL in both types of HF patients. Data were presented as mean values with $95 \%$ confidence intervals (CIs) or as numbers with the percentage.

Propensity score matching (PSM) was used to reduce the bias caused by age, sex, and LVEF in estimating HIIT effects on HF patients [27]. Rebalancing results were described in the supplemental data. To determine the risk and protective factors of 5-year all-cause mortality in the HF patients, the HIIT participants were followed after they had completed 36 HIIT sessions, but the MDP subjects were tracked from inclusion in the study. The choices of these index dates were for the reduction of the immortal time bias. Multivariate Cox regression was conducted to estimate adjusted hazard ratios (aHR) of clinical indicators corresponding to the 5-year all-cause mortality.

The Kaplan-Meier survival curves for HF patients based on their exercise status were assessed by $\log$ rank tests. In order to determine the HIIT effects on the 1-year and later long-term survival, landmark analysis was performed with the landmark time set at one year after the initiation of $F / U$. As blunted $\mathrm{CO}$ associated with heightened ventilatory responses during exercise has been observed in $\mathrm{HF}$ patients with $\mathrm{VO}_{2 \text { peak }}$ of $<14 \mathrm{~mL} / \mathrm{kg} / \mathrm{min}$ [22], the patients were further stratified by their $\mathrm{VO}_{2 \text { peak }}$ and LVESD values for comparing their survival curves. The cut point value for $\mathrm{VO}_{2 \text { peak }}$ was $14 \mathrm{~mL} / \mathrm{kg} / \mathrm{min}$ and that for LVESD was $44 \mathrm{~mm}$, which corresponds to $99.9 \%$ of the healthy individual [28]. A $p$-value less than 0.05 was considered as being of statistical significance.

\subsubsection{Functional Principal Component Analysis (FPCA)}

Longitudinal changes in cardiac geometry and $\mathrm{VO}_{2 \text { peak }}$ during $\mathrm{F} / \mathrm{U}$ were used to reflect physiological adaptations to interventions. They were defined as the following:

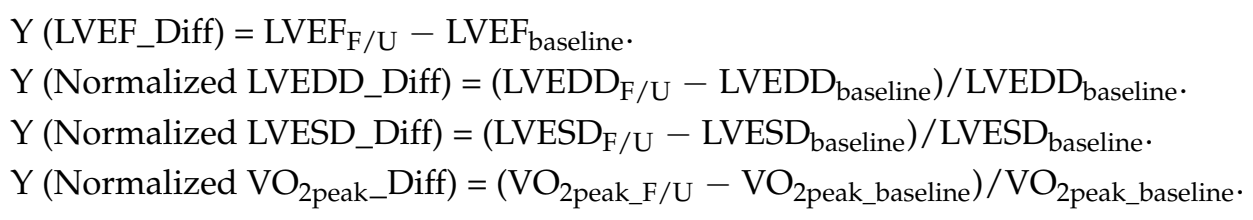

In the FPCA data analysis, the longitudinal response $\mathrm{Y}$ in each individual was modeled by

$$
Y_{i}(d)=m(d)+\sum Z_{j}(d) \beta_{i j}
$$

where $Z_{j}$ was the eigenfunction. The number of eigenfunctions was selected until $95 \%$ of variances were explained by the model (Supplemental Figure S1).

For each subject, the FPCA score (loading coefficients on the space spanned by eigenfunctions) was calculated and the estimated trend for each group was assessed on the basis of the linear combinations of $\sum Z_{\mathrm{j}}(\mathrm{d}) \beta_{\mathrm{ij}}$. Given the two trend curves, we used the maximum distance between these two curves, and the permutation tests were used to provide the $p$-value to indicate how unlikely the observed separations of these two curves based on random assignments of the group [29]. 


\section{Results}

\subsection{Patient Characteristics}

After 1:1 matching via PSM was performed, a total of 202 subjects were included in the analysis, but 32 MDP participants were excluded. They were further divided into the HIIT (72 HFrEF and $29 \mathrm{HFpEF}$ ) and MDP (70 HFrEF and $31 \mathrm{HFpEF)} \mathrm{groups.} \mathrm{The} \mathrm{classification,} \mathrm{inclusion/exclusion} \mathrm{criteria,}$ and F/U algorithm are shown in Figure 1. All HIIT participants exercised as the prescribed intensity. Clinical presentations were similar between the HIIT and MDP participants, except an increase of resting HR in MDP participants (Table 1). Baseline blood chemistries between the two groups were also similar (Supplemental Table S2).

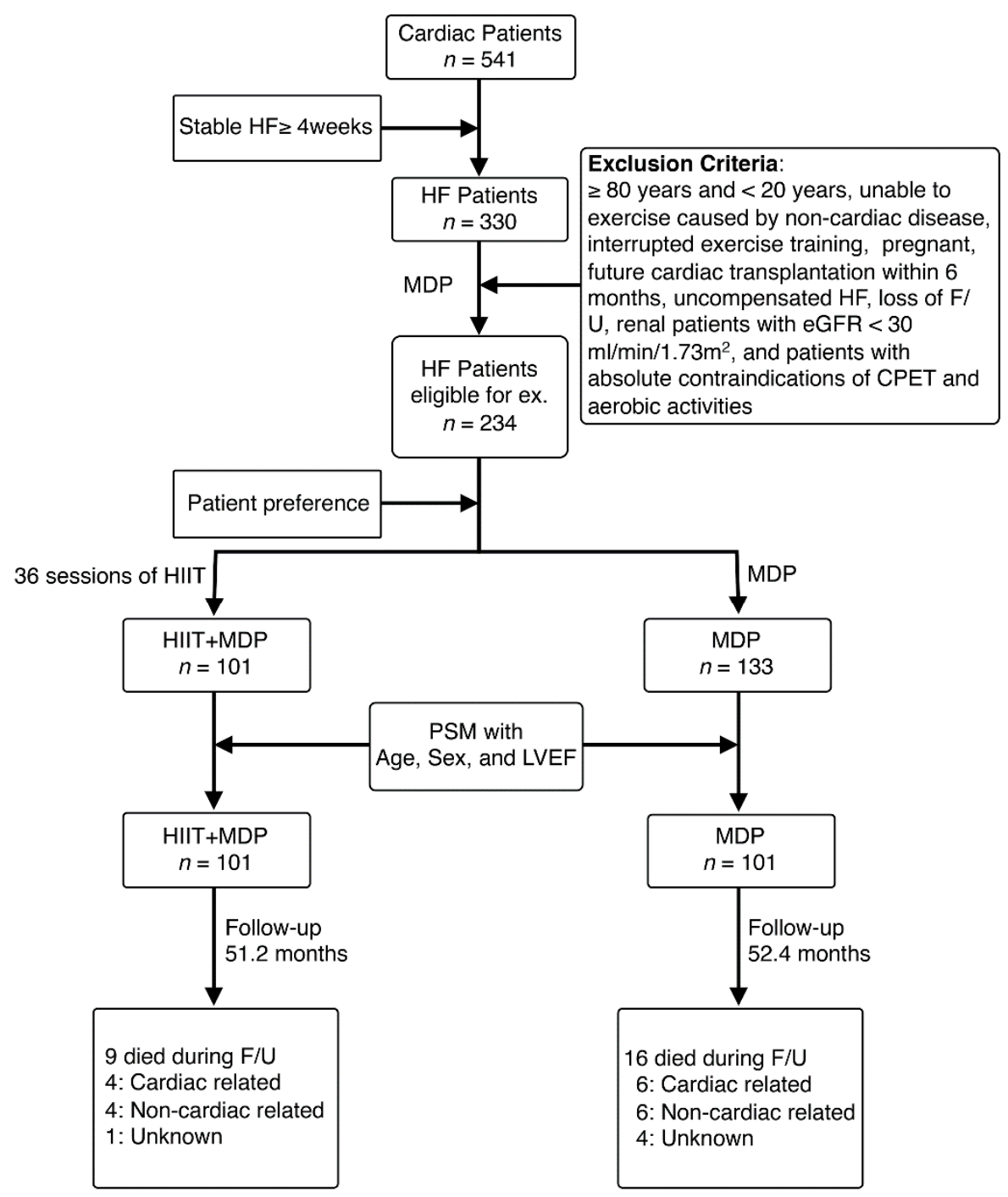

Figure 1. Flowchart of enrolled heart failure (HF) patients during follow-up. The inclusion and exclusion criteria listed in the figure were used to survey HF patients eligible for exercise (ex) training. Enrolled candidates were further divided into simple multidisciplinary disease management program (MDP) or MDP with additional high-intensity interval training (HIIT) groups based on the patient preference. Causes of death were listed at the end of follow-up (F/U). CPET: cardiopulmonary exercise test; eGFR: estimated glomerulus filtration rate; LVEF: left ventricular ejection fraction; PSM: propensity score matching. 
Table 1. Baseline demographics of enrolled heart failure (HF) patients.

\begin{tabular}{|c|c|c|c|c|}
\hline & & $\begin{array}{c}\text { HIIT + MDP } \\
\quad(n=101)\end{array}$ & $\begin{array}{c}\text { MDP } \\
(n=101)\end{array}$ & $p$-Value \\
\hline \multicolumn{2}{|l|}{ HFrEF/HFpEF } & $72 / 29$ & $71 / 30$ & 1.000 \\
\hline \multicolumn{2}{|l|}{ Age, years } & $61.5(58.7-64.2)$ & $62.8(60.1-65.5)$ & 0.492 \\
\hline \multicolumn{2}{|l|}{$\operatorname{Sex}(F / M)$} & $31 / 70$ & $27 / 74$ & 0.641 \\
\hline \multicolumn{2}{|l|}{$\mathrm{BMI}, \mathrm{kg} / \mathrm{m}^{2}$} & $25.7(24.7-26.6)$ & $25.2(24.3-26.2)$ & 0.504 \\
\hline \multicolumn{2}{|c|}{ HF duration, month } & $7.76(4.50-11.0)$ & $11.3(7.39-15.3)$ & 0.168 \\
\hline \multicolumn{5}{|c|}{ NYHA Functional Class, $n(\%)$} \\
\hline I & & $2(2)$ & $7(7)$ & \multirow{3}{*}{0.109} \\
\hline II & & $75(74)$ & $78(77)$ & \\
\hline III & & $24(24)$ & $16(16)$ & \\
\hline \multicolumn{5}{|l|}{ Etiology, $n(\%)$} \\
\hline CAD & & $47(47)$ & $46(46)$ & 1.000 \\
\hline DCM & & $19(19)$ & $21(21)$ & 0.860 \\
\hline Hypertension & & $56(55)$ & $62(61)$ & 0.475 \\
\hline \multicolumn{5}{|l|}{ Comorbidity, $n(\%)$} \\
\hline Hyperlipidemia & & $50(50)$ & $50(50)$ & 1.000 \\
\hline $\mathrm{DM}$ & & $42(42)$ & $40(40)$ & 0.886 \\
\hline Arrhythmia & & $34(34)$ & $33(33)$ & 1.000 \\
\hline \multirow{2}{*}{ Resting BP, mmHg } & SBP & 123 (119-128) & $127(122-131)$ & 0.318 \\
\hline & DBP & $76(73-79)$ & $77(74-80)$ & 0.776 \\
\hline Resting HR, bpm & & 77 (75-79) & $81(78-84)$ & $0.040^{b}$ \\
\hline LVEF, \% & & $34.3(31.3-37.2)$ & $37.0(34.1-39.9)$ & 0.190 \\
\hline $\mathrm{BNP}, \mathrm{pg} / \mathrm{mL}^{\mathrm{a}}$ & & $667(508-801)$ & $635(482-787)$ & 0.765 \\
\hline \multicolumn{5}{|l|}{ Medication, $n(\%)$} \\
\hline $\mathrm{ACEI} / \mathrm{ARB}$ & & $82(81)$ & $83(82)$ & 1.000 \\
\hline$\beta$-blocker & & $80(79)$ & $81(80)$ & 1.000 \\
\hline Diuretics & & $56(55)$ & $63(62)$ & 0.391 \\
\hline MRA & & $20(20)$ & $11(11)$ & 0.117 \\
\hline
\end{tabular}

Baseline information was obtained at recruitment or before the intervention. Values are mean $(95 \%$ confidence interval, $\mathrm{CI}$ ) or $n$ (\%). ACEI: angiotensin-converting-enzyme inhibitor; ARB: angiotensin receptor blocker; $\mathrm{BMI}$ : body mass index; BNP: b-type natriuretic peptide; BP: blood pressure; bpm, beats per minute; CAD: coronary artery disease, DBP: diastolic blood pressure; DCM: dilated cardiomyopathy; DM: diabetes mellitus; F/M: female/male; F/U: follow-up; HFrEF: heart failure with left ventricular ejection fraction $\leq 40 \%$; HFpEF: heart failure with left ventricular ejection fraction $>40 \%$; HIIT: high-intensity interval training; HR: heart rate; LVEF: left ventricular ejection fraction; MDP: multidisciplinary disease management program; MRA: mineralocorticoid receptor antagonist; NYHA: New York Heart Association; SBP: systolic blood pressure. ${ }^{\text {a }} 79$ subjects in exercise and 60 subjects in non-exercise groups received baseline BNP examinations. ${ }^{\mathrm{b}}$ Statistical significance was assessed by Student's $t$-test.

\subsection{HIIT Improved $V O_{2 p e a k}$ and Quality of Life}

All participants had an initial CPET. F/U CPET was performed on all HIIT participants. In the HIIT participants, significant increases $(p<0.001)$ of $\mathrm{VO}_{2 \text { peak }}$ in HFrEF (post-HIIT vs. pre-HIIT $=$ $20.5 \mathrm{~mL} / \mathrm{kg} / \mathrm{min}$ vs. $17.2 \mathrm{~mL} / \mathrm{kg} / \mathrm{min}$ ) and HFpEF (post-HIIT vs. pre-HIIT = $18.5 \mathrm{~mL} / \mathrm{kg} / \mathrm{min}$ vs. $16.2 \mathrm{~mL} / \mathrm{kg} / \mathrm{min}$ ) patients were observed after completing 36 sessions of exercise training. Peak HR, $\mathrm{O}_{2}$ pulse, and PCS also showed this trend. The HFrEF patients but not the HFpEF patients felt better soon after completing HIIT (Table 2). 
Table 2. Effects of HIIT on exercise capacity, cardiac remodeling, and quality of life.

\begin{tabular}{|c|c|c|c|c|}
\hline Type & Assessment & Initial & End-HIIT & $p$-Value \\
\hline \multirow{8}{*}{ HFrEF } & LVEF, \% & $26.8(24.6-28.9)$ & $48.2(44.3-52.1)$ & $<0.001^{\mathrm{a}}$ \\
\hline & LVEDD, mm & $63.2(60.7-65.7)$ & $60.0(57.5-62.5)$ & $0.002^{\mathrm{a}}$ \\
\hline & LVESD, mm & $54.8(52.2-57.4)$ & $45.0(41.9-48.2)$ & $<0.001^{\mathrm{a}}$ \\
\hline & $\mathrm{VO}_{2 \text { peak }}, \mathrm{mL} / \mathrm{kg} / \mathrm{min}$ & $17.2(16.3-18.1)$ & $20.5(19.2-21.8)$ & $<0.001^{\mathrm{a}}$ \\
\hline & Peak HR, bpm & $132(126-137)$ & $139(133-146)$ & $0.001^{\mathrm{a}}$ \\
\hline & Peak $\mathrm{O}_{2}$ pulse, $\mathrm{mL} /$ beat & $9.22(8.61-9.82)$ & $10.2(9.48-10.9)$ & $<0.001^{\mathrm{a}}$ \\
\hline & PCS & $47.0(45.0-48.9)$ & $50.9(48.8-52.9)$ & $<0.001^{\mathrm{a}}$ \\
\hline & MCS & $45.1(42.8-47.3)$ & $47.6(45.2-49.9)$ & $0.012^{\mathrm{a}}$ \\
\hline \multirow{8}{*}{ HFpEF } & LVEF, \% & $52.9(48.5-57.2)$ & $53.1(48.2-57.9)$ & 0.803 \\
\hline & LVEDD, $\mathrm{mm}$ & $54.3(51.3-57.4)$ & $56.3(53.0-59.6)$ & 0.285 \\
\hline & LVESD, $\mathrm{mm}$ & $38.7(35.4-42.0)$ & $40.6(37.1-44.1)$ & 0.387 \\
\hline & \multirow{2}{*}{$\begin{array}{l}\mathrm{VO}_{2 \text { peak }}, \mathrm{mL} / \mathrm{kg} / \mathrm{min} \\
\text { Peak HR, bpm }\end{array}$} & $16.2(15.1-17.4)$ & $18.5(16.8-20.2)$ & $<0.001^{\mathrm{a}}$ \\
\hline & & $136(126-146)$ & $144(133-154)$ & $0.010^{\mathrm{a}}$ \\
\hline & Peak $\mathrm{O}_{2}$ pulse, $\mathrm{mL} /$ beat & $8.49(7.45-9.52)$ & $9.38(8.19-10.6)$ & $0.008^{\mathrm{a}}$ \\
\hline & \multirow{2}{*}{$\begin{array}{ll}\text { SF-36 } & \text { PCS } \\
\text { MCS }\end{array}$} & $45.9(43.0-48.8)$ & $50.8(47.6-53.9)$ & $0.005^{\mathrm{a}}$ \\
\hline & & $42.6(37.9-47.2)$ & $46.5(42.3-50.8)$ & 0.084 \\
\hline
\end{tabular}

All participants had baseline CPET with echocardiography examination, and subsequent $\mathrm{F} / \mathrm{U}$ examinations. Values were mean $(95 \% \mathrm{CI})$. bpm: beats per minute; HFrEF: heart failure with left ventricular ejection fraction $\leq 40 \%$; HFpEF: heart failure with left ventricular ejection fraction $>40 \%$; LVEDD: left ventricle end-diastolic diameter; LVESD: left ventricle end-systolic diameter; LVEF: left ventricular ejection fraction; MCS: mental component score; PCS: physical component score; SF-36: short form $36 ; \mathrm{VO}_{2 \text { peak }}$ : peak oxygen consumption. ${ }^{a}$ Statistical significance was assessed by paired $t$-test.

\subsection{Increased $V O_{2 p e a k}$ and Decreased LVESD Were Protective Factors Against Mortality}

Our results showed that each $1-\mathrm{mL} / \mathrm{kg} / \mathrm{min}$ increase of $\mathrm{VO}_{2 \text { peak }}$ conferred a significant reduction $(p=0.0002)$ of the 5-year all-cause mortality by approximately $58 \%(\mathrm{aHR}=0.4224)$ in HF patients. On the other hand, greater LVESD significantly increased ( $\mathrm{aHR}=1.0767, p=0.0198$ ) mortality in HF patients (Figure 2).

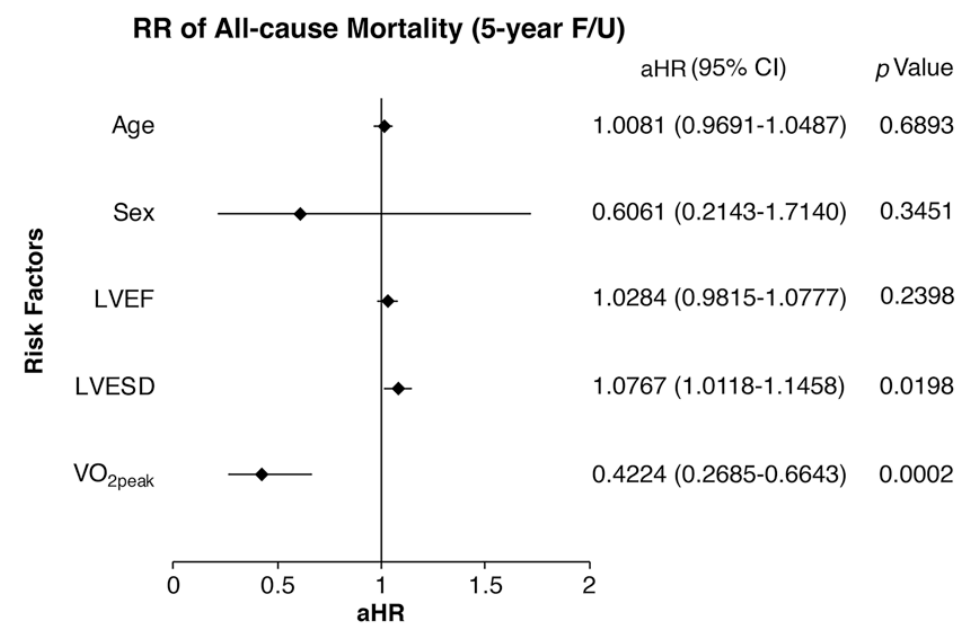

Figure 2. Multivariate Cox regression for estimating the relative risk (RR) of 5-year all-cause mortality in propensity score matching HF patients. Increased LVESD was significantly associated $(p=0.0198)$ with mortality in $\mathrm{HF}$ patients. Increased $\mathrm{VO}_{2 \text { peak }}$ significantly reduced the RR of mortality in $\mathrm{HF}$ patients. Values of adjusted hazard ratio (aHR) are presented as mean $(95 \% \mathrm{CI})$.

A significantly better 8-month overall survival rate $(p=0.044)$ was observed in the HIIT participants compared to the MDP participants (Figure 3A). An increased trend of the cumulative mortality was observed in non-exercise participants at the first and after the fifth $\mathrm{F} / \mathrm{U}$ year (Supplemental Figure S2). HF patients with $\mathrm{VO}_{2 \text { peak }} \geq 14 \mathrm{~mL} / \mathrm{kg} / \mathrm{min}(p<0.001)$ or LVESD $<44 \mathrm{~mm}$ 
$(p=0.017)$ had significantly better 5-year survival rates than those with different manifestations (Figure 3B,C). Those who had both $\mathrm{VO}_{2 \text { peak }} \geq 14 \mathrm{~mL} / \mathrm{kg} / \mathrm{min}$ and LVESD $<44 \mathrm{~mm}$ had the best 5-year overall survival rate of $98.2 \%$, which was significantly better than the rate of $57.3 \%$ in those who simultaneously possessed $\mathrm{VO}_{2 \text { peak }}<14 \mathrm{~mL} / \mathrm{kg} / \mathrm{min}$ and LVESD $\geq 44 \mathrm{~mm}$ (Figure 3D).

A

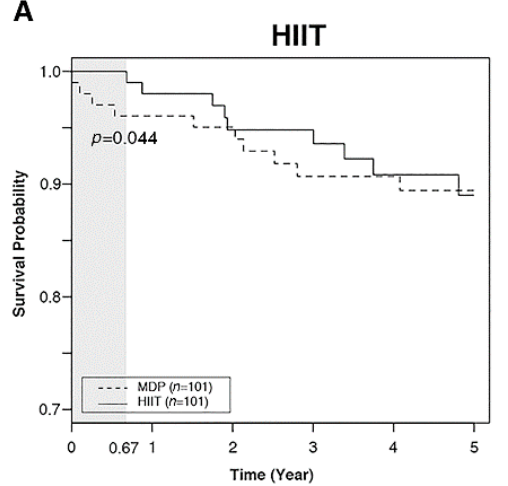

C

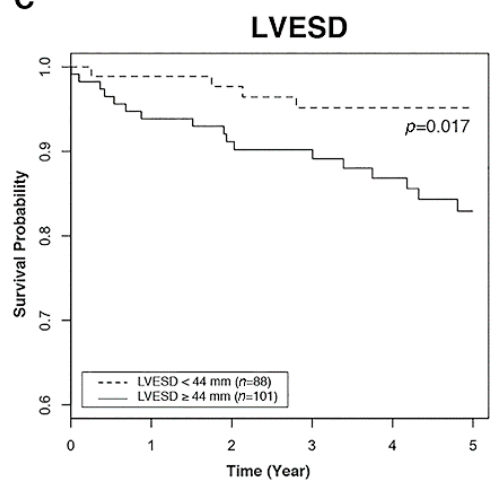

B

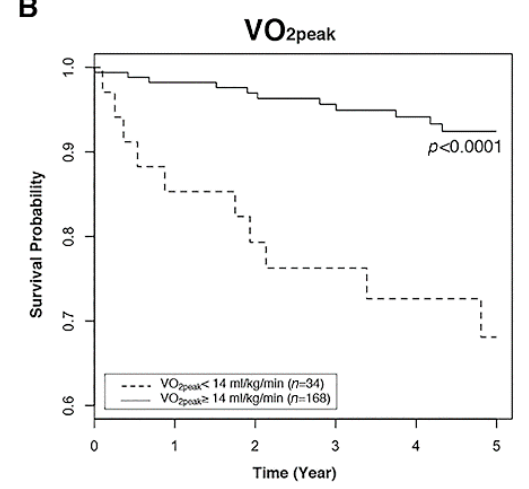

D

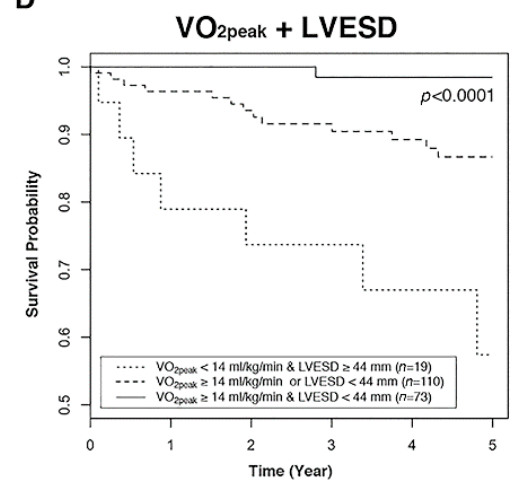

Figure 3. The 5-year overall survival curves analyzed by different categorization in HF patients. (A) HIIT participants $(-)$ had a significantly $(p=0.044)$ increased 8-month (gray zone) survival rate compared to MDP participants (--). (B) HF patients with $\mathrm{VO}_{2 \text { peak }} \geq 14 \mathrm{~mL} / \mathrm{kg} / \mathrm{min}(-)$ had significantly better $(p<0.001) 5$-year survivals than those with $\mathrm{VO}_{2 \text { peak }}<14 \mathrm{~mL} / \mathrm{kg} / \mathrm{min}(---)$. (C) HF patients with LVESD $<44 \mathrm{~mm}(-)$ had significantly better $(p=0.017) 5$-year survivals than those with LVESD $\geq 44 \mathrm{~mm}(-)$. (D) HF patients with both $\mathrm{VO}_{2 \text { peak }} \geq 14 \mathrm{~mL} / \mathrm{kg} / \mathrm{min}$ and LVESD $<44 \mathrm{~mm}$ (-) had significantly better $(p<0.001)$ 5-year survivals than those with $\mathrm{VO}_{2 \text { peak }} \geq 14 \mathrm{~mL} / \mathrm{kg} / \mathrm{min}$ or LVESD $<44 \mathrm{~mm}(---)$, and those with both $\mathrm{VO}_{2 \text { peak }}<14 \mathrm{~mL} / \mathrm{kg} / \mathrm{min}$ and LVESD $\geq 44 \mathrm{~mm}(\cdots \cdots)$.

HIIT increased the proportion of HFrEF patients to have LVESD $<44 \mathrm{~mm}$ (Figure $4 \mathrm{~A}$ ) and HFpEF patients to have $\mathrm{VO}_{2 \text { peak }} \geq 14 \mathrm{~mL} / \mathrm{kg} / \mathrm{min}$ (Figure 4C). In HIIT participants with HFrEF, those with LVESD $<44 \mathrm{~mm}$ after completing 36 sessions of HIIT $(p=0.005)$ showed a significant association with improved long-term survival rate compared to those with LVESD $\geq 44 \mathrm{~mm}$ (Figure 4B). In HIIT participants with $\mathrm{HFpEF}$, those with $\mathrm{VO}_{2 \text { peak }} \geq 14 \mathrm{~mL} / \mathrm{kg} / \mathrm{min}$ after completing 36 sessions of HIIT showed a significant association with the improved $(p=0.01)$ survival rates compared to those with $\mathrm{VO}_{2 \text { peak }}<14 \mathrm{~mL} / \mathrm{kg} / \mathrm{min}$ (Figure $4 \mathrm{D}$ ). Causes of death were similar between the exercise and non-exercise groups (Supplemental Table S3). 
A

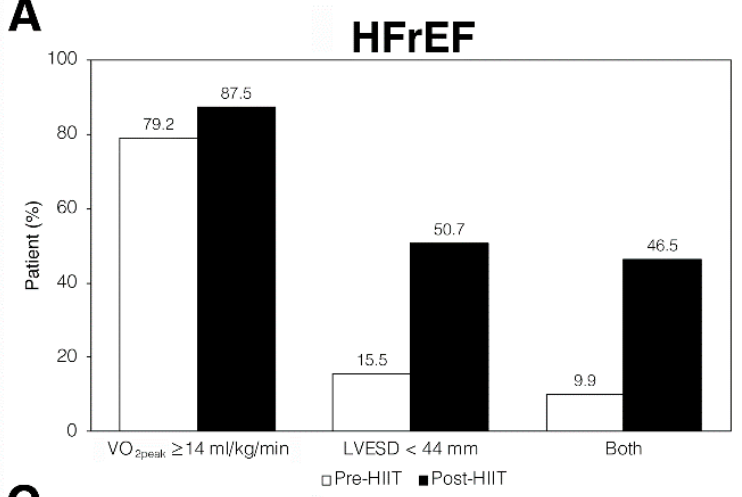

C

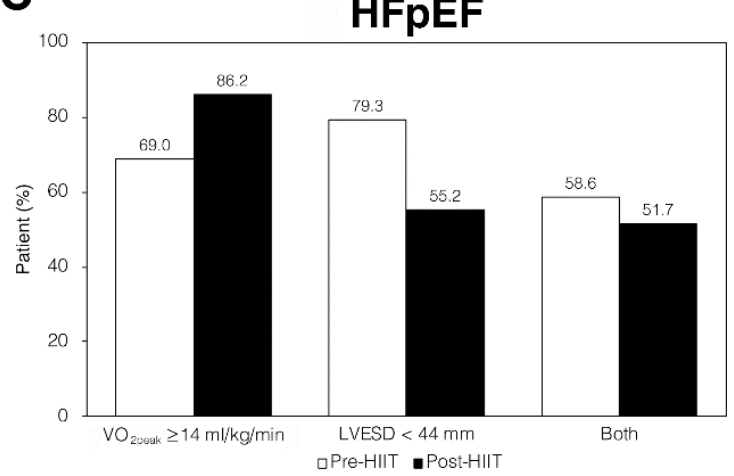

B

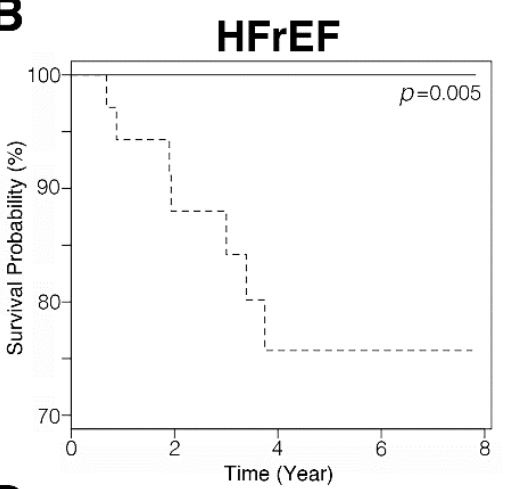

D

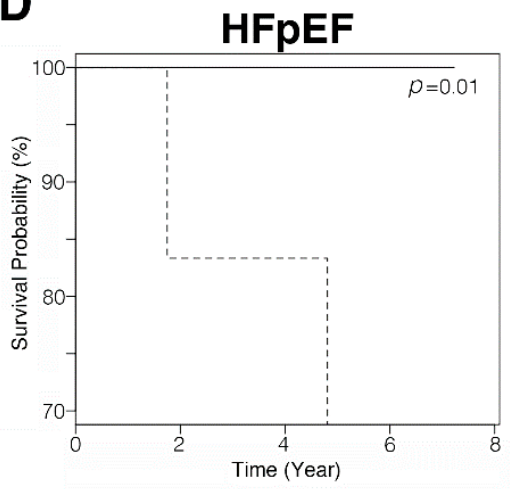

Figure 4. Alterations of $\mathrm{VO}_{2 \text { peak }}$, LVESD, and both of the two indicators in HFrEF and HFpEF patients after HIIT. (A) Among HFrEF patients, 15.5\% had LVESD <44 mm before exercise training (white bars). Proportion of HFrEF patients with LVESD $<44 \mathrm{~mm}$ increased to about $50 \%$ after HIIT (black bars). (B) HFrEF patients with LVESD $<44 \mathrm{~mm}(-)$ had a significantly greater survival probability $(p=0.005)$ than those with LVESD $\geq 44 \mathrm{~mm}$ (---). (C) Among HFpEF patients, $69.0 \%$ had $\mathrm{VO}_{2 \text { peak }} \geq 14 \mathrm{~mL} / \mathrm{kg} / \mathrm{min}$ before exercise training (white bars). The proportion of $\mathrm{HFpEF}$ patients with $\mathrm{VO}_{2 \text { peak }} \geq 14 \mathrm{~mL} / \mathrm{kg} / \mathrm{min}$ increased to $86.2 \%$ after HIIT (black bars). (D) HFpEF patients with $\mathrm{VO}_{2 \text { peak }} \geq 14 \mathrm{~mL} / \mathrm{kg} / \mathrm{min}$ (一) had significantly greater survival probability $(p=0.01)$ than those with $\mathrm{VO}_{2 \text { peak }}<14 \mathrm{~mL} / \mathrm{kg} / \mathrm{min}(---)$.

\subsection{HIIT Reversed Cardiac Remodeling In HFrEF Patients}

The mean LVEDD was decreased significantly $(p=0.002)$ from $63.2 \mathrm{~mm}$ to $60.0 \mathrm{~mm}$, and the mean LVESD was decreased significantly $(p<0.001)$ from $54.8 \mathrm{~mm}$ to $45.0 \mathrm{~mm}$ when we compared before and after completing HIIT in the HFrEF patients. A significant $(p<0.001)$ increase in LVEF from $26.8 \%$ to $48.2 \%$ was also found in these subjects (Table 2). The relief of cardiac stress in HFrEF patients after HIIT reflected in the significant decrease $(p<0.001)$ in BNP level (Supplemental Figure S3).

Among HIIT participants, the median echocardiographic examination time was 4 (range 2-7), and 24 of them did not receive F/U echocardiographic examinations after completing HIIT. The mean echocardiographic examination interval during exercise training was 4.2 (3.6-4.6) months, which extended to 14.4 (13.4-15.4) months after stopping exercise training. Among MDP participants, the median echocardiographic examination time was 3 (range 1-8), and the mean examination interval was $14.6(13.8-15.4)$ months.

During the long-term observation, 35 HFrEF patients had LVESD $<44 \mathrm{~mm}$ after HIIT, while the other 35 HFrEF patients showed otherwise. Among those patients with reduced LVESD, 24 such patients had F/U LVESD measurements and 18 of them maintained LVESD $<44 \mathrm{~mm}$ at their most recent measurement. On the other hand, among those patients whose LVESD did not improve to the desired level, 23 of them had subsequent LVESD measurement during F/U. Among the 23 subjects, $3 \mathrm{had}$ reduced LVESD to less than $44 \mathrm{~mm}$, and 20 of them this value remained greater than $44 \mathrm{~mm}$. The 5-year trend curves of echocardiographic findings between the HIIT and MDP participants are 
shown in Figure 5. Short-term HIIT was significantly associated with reduced LVESD $(p=0.0052)$ in HFrEF patients compared to the MDP participants.

A

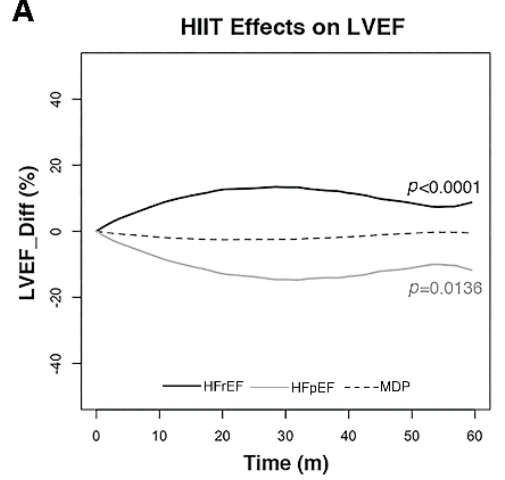

B

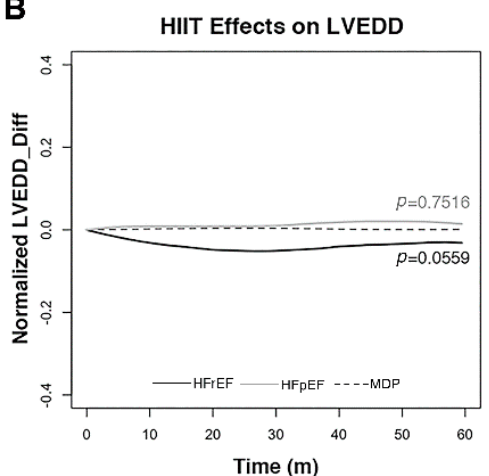

C

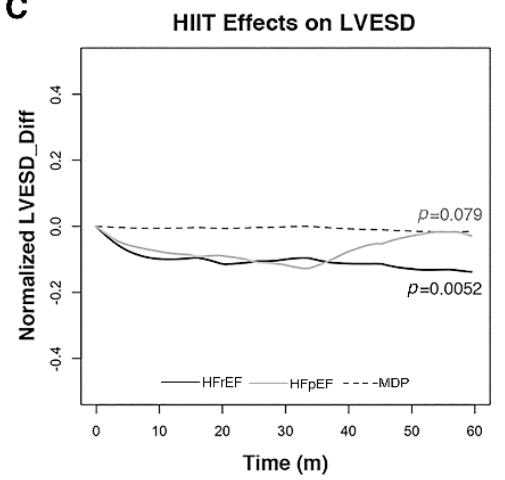

Figure 5. Five-year trend curves for HIIT effects on LV dimensions. Differences of LVEF (LVEF_Diff), LVEDD (Normalized LVEDD_Diff), and LVESD (Normalized LVESD_Diff) in HIIT participants with HFrEF (-), HFpEF (-), or MDP (---) were shown. (A) LVEF increased significantly in $\operatorname{HFrEF}(p<0.0001)$, but decreased significantly in $\operatorname{HFpEF}(p=0.0136)$ patients compared to the MDP participants. (B) In the HIIT group, LVEDD decreased in HFrEF, but increased in HFpEF patients non-significantly compared to the MDP participants. (C) In the HIIT group, LVESD decreased significantly $(p=0.0052)$ in HFrEF patients, but non-significantly in HFpEF patients compared to the MDP participants.

\subsection{HIIT Induced Mild LV Dilatation and Decreased LVEF in HFpEF Patients}

Non-significant increases in LV dimensions and LVEF were detected in the HFpEF patients during HIIT (Table 2). In the 5-year trend curves for them, HIIT non-significantly altered LVESD and LVEDD, but significantly decreased ( $p=0.0136$ ) LVEF as compared to the MDP subject (Figure 5).

\section{Discussion}

LV remodeling in HF patients is characterized by chamber enlargement associated with advancing contractile dysfunction regardless of the inciting cause [30]. This investigation is the first to demonstrate that short-term HIIT induces different types of LV remodeling to improve $\mathrm{VO}_{2 \text { peak }}$ in different types of HF patients, which protects against mortality and finally improves survival. Promising anti-LV remodeling effects after HIIT have been identified in HFrEF patients during the 8-year longitudinal follow-up. The HIIT-induced increases of $\mathrm{VO}_{2 \text { peak }}$ in HFpEF patients may be associated with non-significant LV dilatation, and this cardiac response is different from the cardiac adaptation to HIIT in HFrEF patients. Our long-term observations (Figure 3) also support the previous report that the improvement of $\mathrm{VO}_{2 \text { peak }}$ after exercise training is a dominant prognostic marker in the reduction of all-cause mortality [31]. The present work also addressed that HF patients with $\mathrm{VO}_{2 \text { peak }}$ $\geq 14 \mathrm{~mL} / \mathrm{kg} / \mathrm{min}$ and/or LVESD $<44 \mathrm{~mm}$ could have better 5-year overall survival rates than the rest of HF patients.

LV volume measurements have long been known as an important surrogate marker for HF

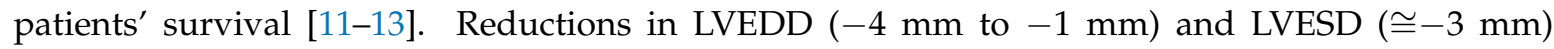
accompanied by $-7 \%$ to $16 \%$ changes of LVEF were observed in HFrEF patients with HIIT at $50-95 \%$ of $\mathrm{VO}_{2 \text { peak }}[8,9,15]$ or MICT at $60-70 \%$ of $\mathrm{VO}_{2 \text { peak }}[12,13]$. The various alterations of $\mathrm{LV}$ dimensions in different exercise training studies for HFrEF patients are considered to be related to the different exercise training styles or prescribed exercise intensities [32,33]. The reported exercise compliance, i.e., how many participants exercised at the prescribed intensities, varied from $49-100 \%[8,9,15]$, which may also contribute to the inconsistent conclusions. Significant decreases of LVEDD and LVESD associated with a significant increase of LVEF in HFrEF patients after completing exercise training 
were identified in the present work. High exercise compliance from all our HIIT participants might enhance the observed anti-LV remodeling effects in this study.

HFpEF patients in the study had mild LV enlargement before exercise training [29], in accordance with a prior report [34]. Non-significant LV dilatation was observed in HFpEF patients during HIIT in this study, which was also identified in the previous report [26]. This phenomenon was similar to patients with LV hypertrophy (LVH) [35]. Besides, LV dilatation is also a typical finding in exercise-induced cardiac remodeling (EICR), which reflects a physiological adaptation to the exercise-related increase of preload in healthy persons [36,37]. Therefore, further investigations are required to determine whether the LV dilatation in HFpEF patients is a downstream presentation of EICR or a cardiac adaptation to LVH.

In comparison with the $4 \%$ to $5 \%$ increase of $\mathrm{VO}_{2 \text { peak }}$ in $\mathrm{HFrEF}$ patients with $\mathrm{MICT}$ at $70 \%$ heart rate reserve $[15,38]$, our work has shown that HIIT provided a robust stimulus of approximately $20 \%$ increase of $\mathrm{VO}_{2 \text { peak }}$ and an associated decrease of $\mathrm{LV}$ dimensions in the HFrEF patients. Therefore, the improvement of exercise capacity in HFrEF patients is probably related to the reversal of LV remodeling during HIIT. HIIT increased the $\mathrm{VO}_{2 \text { peak }}$ by approximately $14 \%$ in $\mathrm{HFpEF}$ patients with non-significant LV enlargement in the study. The improvement of $\mathrm{VO}_{2 \text { peak }}$ in $\mathrm{HFpEF}$ patients after HIIT may be majorly caused by peripheral adaptations [26] instead of a central cardiac response because slightly reduced LVEF under normal cardiac pumping function has been detected in HFpEF patients during this long-term $\mathrm{F} / \mathrm{U}$.

Outcomes have varied substantially across studies of HF patients with heterogeneity in included participants, classifications of cardiac functions, and care programs [39]. A Canadian hospital-based study for admitted HF patients reported 1-year all-cause mortality of $26 \%$ in HFrEF patients and $22 \%$ in HF patients with LVEF $>50 \%$ [40]. A better 2-year all-cause mortality of $15 \%$ in HF patients was reported in an Eastern community-based cohort study [19]. A high 1-year survival rate in HF patients without HIIT was also found in the study. Ethnic or genomic differences are proposed to explain the better survivals of East Asian HF patients than those of Western and Central Europe following an acute HF episode [41].

Although HIIT was significantly associated with reduced death events only within the first F/ U year, an increased trend of cumulative mortality has been observed in non-exercise participants during our long-term F/U. Physiological adaptations after exercise training may protect HIIT participants against death. Suppression of cerebral/muscle hemodynamics and ventilatory abnormality reduces functional capacity in $\mathrm{HF}$ patients with $\mathrm{VO}_{2 \text { peak }}<14 \mathrm{~mL} / \mathrm{kg} / \mathrm{min}$ [25], which may further induce high 5-year mortality. LVESD $\geq 44 \mathrm{~mm}$ has been demonstrated to be associated with poor long-term prognosis for HF patients, which hints that LV remodeling is closely related to the mortality in cardiac patients [30]. In contrast to the non-significant reduction of all-cause mortality in HF patients under MICT [38], our cohort study has indicated that HIIT might protect HF patients from deaths. The increased maximum exercise capacity [42] in association with the exercise-induced reversal of LV remodeling may be attributable to the improved survival in HF patients.

\section{Limitations}

The European Society of Cardiology has defined HF patients having LVEF of $40-49 \%$ as HF with mid-range EF in 2016 [1]. Thus, it is less likely to classify this group of patients without guideline in 2009. All included subjects received several echocardiographic examinations during F/U; however, the majority of subjects do not have the examination near the end of F/U. From the aspect of study design, it is of great benefit to perform the additional examination near the end of $\mathrm{F} / \mathrm{U}$. Although propensity score matching was performed to reduce the selection biases, it is our limitation that the residual selection bias might remain in our data. The low number of death events and the choice of M-mode echocardiographic survey for LV geometry also limit our study. Other weakness includes that patients' physical activities at home were not regularly assessed. Therefore, long-term F/U for the change in lifestyle in our HF patients after exercise training is required. 


\section{Conclusions}

This 8-year cohort study has demonstrated that HIIT improves the maximum exercise capacity of HF patients, in accordance with previous investigations [7-9,11,15,26], and may become a significant prognostic factor of long-term survival in HF patients. The reversal of pathological LV remodeling in HF patients after exercise training is probably beneficial for their long-term survival. HF patients with $\mathrm{VO}_{2 \text { peak }} \geq 14 \mathrm{~mL} / \mathrm{kg} / \mathrm{min}$ and/or LVESD $<44 \mathrm{~mm}$ after HIIT were identified to have a better survival probability in this long-term follow-up.

Supplementary Materials: The following are available online at http:/ /www.mdpi.com/2077-0383/8/3/409/s1, Figure S1: In FPCA data analysis, each individual longitudinal response of LVEF_Diff, normalized $\mathrm{VO}_{2 \text { peak_Diff, }}$ normalized LVEDD_Diff or normalized LVESD_Diff were modeled by eigenfunctions and are selected until 95\% of variances are explained by the model, Figure S2: Landmark analysis for cumulative mortality events. The landmark time was set at one year $(\cdots \cdots)$. Although the difference between the exercise $(-)$ and non-exercise (一) participants was not significant, the increased trend of cumulative mortality was observed in non-exercise participants in the first and the 8th follow-up years, Figure S3: Different stress responses to HIIT between HFrEF (gray) and HFpEF (white) patients.105 HFrEF patients (58 HIIT and 47 MDP participants) and $41 \mathrm{HFpEF}$ patients (21 HIIT and 13 MDP participants) had baseline b-type natriuretic peptide (BNP) levels. Subsequent evaluations were done in $43 \mathrm{HFrEF}$ (24 HIIT and 19 MDP participants) and 15 HFpEF patients (6 HIIT and 9 MDP participants). We observed that HIIT induced a significant decrease $(p<0.001)$ of BNP (mean $(95 \% \mathrm{CI})$ ) from 518 (564-936) $\mathrm{pg} / \mathrm{mL}$ to 92.8 (86-222) $\mathrm{pg} / \mathrm{mL}$ in HFrEF patients but no significant changes detected in HFpEF patients. The bar represented median with 1st-3rd quartiles and standard error covered the minimum to the maximum values. Outliers were shown in dots, Table S1: List of all variables in the study, Table S2: Baseline blood chemistry in enrolled HF patients.

Author Contributions: Conceptualization, C.-C.H., T.-C.F., S.-S.Y., and J.-S.W.; Data curation, C.-C.H., S.-S.Y., C.-H.W., M.-H.L., Y.-C.S., W.-J.C., and J.-S.W.; Formal analysis, C.-C.H. and S.-S.Y.; Funding acquisition, C.-C.H., T.-C.F. and J.-S.W.; Methodology, C.-C.H. and S.-S.Y.; Writing-Original draft, C.-C.H.; Review and Editing, S.-S.Y. and J.-S.W. All authors critically revised the manuscript for important intellectual content and approved the final manuscript.

Funding: The study was granted by the Academia Sinica (Mathematics in Biology \& AS-104-TP-A07), Keelung Chang Gung Medical Research Program (CLRPG2H0041, CMRPG2C0421, and CMRPG2C0422) and the Ministry of Science and Technology, Taiwan (MOST 104-2314-B-182-004 and 105-2314-B-182-010) for pure academic interests.

Acknowledgments: We thank Ting-Shuo Huang in the Department of General Surgery, Keelung Change Gung University, for providing statistical advice. Pei-Hsun Yuan in the Department of Physical Medicine and Rehabilitation, and Tai-Yang Chen in Community Medicine Research Center, Keelung Chang Gung Memorial Hospital contributed greatly in collecting clinical information.

Conflicts of Interest: The authors declare no conflict of interest.

\section{References}

1. Ponikowski, P.; Voors, A.A.; Anker, S.D.; Bueno, H.; Cleland, J.G.F.; Coats, A.J.S.; Falk, V.; González-Juanatey, J.R.; Harjola, V.-P.; Jankowska, E.A.; et al. 2016 ESC Guidelines for the diagnosis and treatment of acute and chronic heart failure. Eur. Heart J. 2016, 37, 2129-2200. [CrossRef] [PubMed]

2. Ambrosy, A.P.; Fonarow, G.C.; Butler, J.; Chioncel, O.; Greene, S.J.; Vaduganathan, M.; Nodari, S.; Lam, C.S.P.; Sato, N.; Shah, A.N.; et al. The global health and economic burden of hospitalizations for heart failure: Lessons learned from hospitalized heart failure registries. J. Am. Coll. Cardiol. 2014, 63, 1123-1133. [CrossRef]

3. Bui, A.L.; Horwich, T.B.; Fonarow, G.C. Epidemiology and risk profile of heart failure. Nat. Rev. Cardiol. 2011, 8, 30-41. [CrossRef] [PubMed]

4. Sakata, Y.; Shimokawa, H. Epidemiology of heart failure in Asia. Circ. J. 2013, 77, 2209-2217. [CrossRef]

5. Levy, D.; Kenchaiah, S.; Larson, M.G.; Benjamin, E.J.; Kupka, M.J.; Ho, K.K.; Murabito, J.M.; Vasan, R.S. Long-term trends in the incidence of and survival with heart failure. N. Engl. J. Med. 2002, 347, 1397-1402. [CrossRef]

6. Cook, C.; Cole, G.; Asaria, P.; Jabbour, R.; Francis, D.P. The annual global economic burden of heart failure. Int. J. Cardiol. 2014, 171, 368-376. [CrossRef]

7. Gossard, D.; Haskell, W.L.; Taylor, C.B.; Mueller, J.K.; Rogers, F.; Chandler, M.; Ahn, D.K.; Miller, N.H.; DeBusk, R.F. Effects of low- and high-intensity home-based exercise training on functional capacity in healthy middle-aged men. Am. J. Cardiol. 1986, 57, 446-449. [CrossRef] 
8. Wisløff, U.; Støylen, A.; Loennechen, J.P.; Bruvold, M.; Rognmo, O.; Haram, P.M.; Tjønna, A.E.; Helgerud, J.; Slørdahl, S.A.; Lee, S.J.; et al. Superior cardiovascular effect of aerobic interval training versus moderate continuous training in heart failure patients: A randomized study. Circulation 2007, 115, 3086-3094. [CrossRef]

9. Fu, T.C.; Wang, C.H.; Lin, P.S.; Hsu, C.C.; Cherng, W.J.; Huang, S.C.; Liu, M.H.; Chiang, C.L.; Wang, J.S. Aerobic interval training improves oxygen uptake efficiency by enhancing cerebral and muscular hemodynamics in patients with heart failure. Int. J. Cardiol. 2013, 167, 41-50. [CrossRef] [PubMed]

10. Angadi, S.S.; Mookadam, F.; Lee, C.D.; Tucker, W.J.; Haykowsky, M.J.; Gaesser, G.A. High-intensity interval training vs. moderate-intensity continuous exercise training in heart failure with preserved ejection fraction: A pilot study. J. Appl. Physiol. 2015, 119, 753-758. [CrossRef]

11. Wang, J.S.; Fu, T.C.; Lien, H.Y.; Wang, C.H.; Hsu, C.C.; Wu, W.C.; Chien, Y.W.; Cherng, W.J. Effect of aerobic interval training on erythrocyte rheological and hemodynamic functions in heart failure patients with anemia. Int. J. Cardiol. 2013, 168, 1243-1250. [CrossRef] [PubMed]

12. Hambrecht, R.; Gielen, S.; Linke, A.; Fiehn, E.; Yu, J.; Walther, C.; Schoene, N.; Schuler, G. Effects of exercise training on left ventricular function and peripheral resistance in patients with chronic heart failure: A randomized trial. JAMA 2000, 283, 3095-3101. [CrossRef]

13. Giannuzzi, P.; Temporelli, P.L.; Corra, U.; Tavazzi, L. Antiremodeling effect of long-term exercise training in patients with stable chronic heart failure: Results of the Exercise in Left Ventricular Dysfunction and Chronic Heart Failure (ELVD-CHF) Trial. Circulation 2003, 108, 554-559. [CrossRef] [PubMed]

14. Pandey, A.; Parashar, A.; Kumbhani, D.; Agarwal, S.; Garg, J.; Kitzman, D.; Levine, B.; Drazner, M.; Berry, J. Exercise training in patiensts with heart failure and preserved ejection fraction: Meta-analysis of randomized control trials. Circ. Heart Fail. 2015, 8, 33-40. [CrossRef]

15. Ellingsen, Ø.; Halle, M.; Conraads, V.; Støylen, A.; Dalen, H.; Delagardelle, C.; Larsen, A.I.; Hole, T.; Mezzani, A.; Van Craenenbroeck, E.M.; et al. High-intensity interval training in patients with heart failure with reduced ejection fraction. Circulation 2017, 135, 839-849. [CrossRef] [PubMed]

16. Benchimol, E.I.; Smeeth, L.; Guttmann, A.; Harron, K.; Moher, D.; Petersen, I.; Sorensen, H.T.; von Elm, E.; Langan, S.M. The REporting of studies Conducted using Observational Routinely-collected health Data (RECORD) statement. PLoS Med. 2015, 12, e1001885. [CrossRef] [PubMed]

17. McKee, P.A.; Castelli, W.P.; McNamara, P.M.; Kannel, W.B. The natural history of congestive heart failure: The framingham study. N. Engl. J. Med. 1971, 285, 1441-1446. [CrossRef] [PubMed]

18. Working Group on Cardiac Rehabilitation \& Exercise Physiology; Working Group on Heart Failure of the European Society of Cardiology. Recommendations for exercise testing in chronic heart failure patients. Eur. Heart J. 2001, 22, 37-45. [CrossRef]

19. Lee, M.F.; Chen, W.S.; Fu, T.C.; Liu, M.H.; Wang, J.S.; Hsu, C.C.; Huang, Y.Y.; Cherng, W.J.; Wang, C.H. Non-invasive cardiac index monitoring during cardiopulmonary functional testing provides additional prognostic value in patients after acute heart failure. Int. Heart J. 2012, 53, 364-369. [CrossRef]

20. Mao, C.T.; Liu, M.H.; Hsu, K.H.; Fu, T.C.; Wang, J.S.; Huang, Y.Y.; Yang, N.I.; Wang, C.H. Effect of multidisciplinary disease management for hospitalized heart failure under a national health insurance programme. J. Cardiovasc. Med. 2015, 16, 616-624. [CrossRef]

21. Pescatello, L.S.; Arena, R.; Riebe, D.; Thompson, P.D. ACSM's Guidelines for Exercise Testing and Prescription, 9th ed.; Wolters Kluwer/Lippincott Williams \& Wilkins: Philadelphia, PA, USA, 2014.

22. Bruggink, A.H.; de Jonge, N.; van Oosterhout, M.F.; Van Wichen, D.F.; de Koning, E.; Lahpor, J.R.; Kemperman, H.; Gmelig-Meyling, F.H.; de Weger, R.A. Brain natriuretic peptide is produced both by cardiomyocytes and cells infiltrating the heart in patients with severe heart failure supported by a left ventricular assist device. J. Heart Lung Transplant. 2006, 25, 174-180. [CrossRef]

23. Carr, K.W.; Engler, R.L.; Forsythe, J.R.; Johnson, A.D.; Gosink, B. Measurement of left ventricular ejection fraction by mechanical cross-sectional echocardiography. Circulation 1979, 59, 1196-1206. [CrossRef]

24. Lang, R.M.; Bierig, M.; Devereux, R.B.; Flachskampf, F.A.; Foster, E.; Pellikka, P.A.; Picard, M.H.; Roman, M.J.; Seward, J.; Shanewise, J.S.; et al. Recommendations for chamber quantification: A report from the american society of echocardiography's guidelines and standards committee and the chamber quantification writing group, developed in conjunction with the european association of echocardiography, a branch of the european society of cardiology. J. Am. Soc. Echocardiogr. 2005, 18, 1440-1463. 
25. Fu, T.C.; Wang, C.H.; Hsu, C.C.; Cherng, W.J.; Huang, S.C.; Wang, J.S. Suppression of cerebral hemodynamics is associated with reduced functional capacity in patients with heart failure. Am. J. Physiol. Heart Circ. Physiol. 2011, 300, H1545-H1555. [CrossRef]

26. Fu, T.C.; Yang, N.I.; Wang, C.H.; Cherng, W.J.; Chou, S.L.; Pan, T.L.; Wang, J.S. Aerobic Interval Training Elicits Different Hemodynamic Adaptations Between Heart Failure Patients with Preserved and Reduced Ejection Fraction. Am. J. Phys. Med. Rehabil. 2016, 95, 15-27. [CrossRef]

27. Rosenbaum, P.R.; Rubin, D.B. The central role of the propensity score in observational studies for causal effects. Biometrika 1983, 70, 41-55. [CrossRef]

28. Kou, S.; Caballero, L.; Dulgheru, R.; Voilliot, D.; De Sousa, C.; Kacharava, G.; Athanassopoulos, G.D.; Barone, D.; Baroni, M.; Cardim, N.; et al. Echocardiographic reference ranges for normal cardiac chamber size: Results from the NORRE study. Eur. Heart J. Cardiovasc. Imaging 2014, 15, 680-690. [CrossRef]

29. Yao, F.; Müller, H.G.; Wang, J.L. Functional Data Analysis for Sparse Longitudinal Data. J. Am. Stat. Assoc. 2005, 100, 577-590. [CrossRef]

30. Konstam, M.A.; Kramer, D.G.; Patel, A.R.; Maron, M.S.; Udelson, J.E. Left ventricular remodeling in heart failure: Current concepts in clinical significance and assessment. J. Am. Coll. Cardiol. 2011, 4, 98-108. [CrossRef]

31. Cahalin, L.P.; Chase, P.; Arena, R.; Myers, J.; Bensimhon, D.; Peberdy, M.A.; Ashley, E.; West, E.; Forman, D.E.; Pinkstaff, S.; et al. A meta-analysis of the prognostic significance of cardiopulmonary exercise testing in patients with heart failure. Heart Fail. Rev. 2013, 18, 79-94. [CrossRef]

32. Ismail, H.; McFarlane, J.R.; Nojoumian, A.H.; Dieberg, G.; Smart, N.A. Clinical outcomes and cardiovascular responses to different exercise training intensities in patients with heart failure: A systematic review and meta-analysis. JACC. Heart Fail. 2013, 1, 514-522. [CrossRef]

33. Wang, J.S. Effect of exercise training on exercise capacity and quality of life in patients with heart failure. Int. J. Cardiol. 2018, 261, 144-145. [CrossRef]

34. Liu, S.; Guan, Z.; Jin, X.; Meng, P.; Wang, Y.; Zheng, X.; Jia, D.; Ma, C.; Yang, J. Left ventricular diastolic and systolic dyssynchrony and dysfunction in heart failure with preserved ejection fraction and a narrow QRS complex. Int. J. Med. Sci. 2018, 15, 108-114. [CrossRef]

35. Thaman, R.; Gimeno, J.R.; Reith, S.; Esteban, M.T.; Limongelli, G.; Murphy, R.T.; Mist, B.; McKenna, W.J.; Elliott, P.M. Progressive left ventricular remodeling in patients with hypertrophic cardiomyopathy and severe left ventricular hypertrophy. J. Am. Coll. Cardiol. 2004, 44, 398-405. [CrossRef]

36. Weiner, R.B.; Baggish, A.L. Exercise-induced cardiac remodeling. Prog. Cardiovasc. Dis. 2012, 54, 380-386. [CrossRef]

37. Dawes, T.J.; Corden, B.; Cotter, S.; de Marvao, A.; Walsh, R.; Ware, J.S.; Cook, S.A.; O’Regan, D.P. Moderate physical activity in healthy adults Is associated with cardiac remodeling. Circ. Cardiovasc. Imaging 2016, 9, e004712. [CrossRef]

38. O'Connor, C.M.; Whellan, D.J.; Lee, K.L.; Keteyian, S.J.; Cooper, L.S.; Ellis, S.J.; Leifer, E.S.; Kitzman, D.W.; Blumenthal, J.A.; Rendall, D.S.; et al. Efficacy and safety of exercise training in patients with chronic heart failure: HF-Action randomized controlled trial. JAMA 2009, 301, 1439-1450. [CrossRef]

39. Lam, C.S.; Donal, E.; Kraigher-Krainer, E.; Vasan, R.S. Epidemiology and clinical course of heart failure with preserved ejection fraction. Eur. J. Heart Fail. 2011, 13, 18-28. [CrossRef]

40. Bhatia, R.S.; Tu, J.V.; Lee, D.S.; Austin, P.C.; Fang, J.; Haouzi, A.; Gong, Y.; Liu, P.P. Outcome of heart failure with preserved ejection fraction in a population-based study. N. Engl. J. Med. 2006, 355, 260-269. [CrossRef]

41. Akiyama, E.; Van Aelst, L.N.L.; Arrigo, M.; Lassus, J.; Miro, O.; Celutkiene, J.; Choi, D.J.; Cohen-Solal, A.; Ishihara, S.; Kajimoto, K.; et al. East Asia may have a better 1-year survival following an acute heart failure episode compared with Europe: Results from an international observational cohort. Eur. J. Heart Fail. 2018, 20, 1071-1075. [CrossRef]

42. Myers, J.; Prakash, M.; Froelicher, V.; Do, D.; Partington, S.; Atwood, J.E. Exercise capacity and mortality among men referred for exercise testing. N. Engl. J. Med. 2002, 346, 793-801. [CrossRef] [PubMed]

(C) 2019 by the authors. Licensee MDPI, Basel, Switzerland. This article is an open access article distributed under the terms and conditions of the Creative Commons Attribution (CC BY) license (http://creativecommons.org/licenses/by/4.0/). 